\title{
COMPARATIVO DOS CUSTOS INDUSTRIAIS E ADMINISTRATIVOS NAS USINAS DE AÇÚCAR E ÁLCOOL DA DR-10: REGIÃO DE PRESIDENTE PRUDENTE
}

\author{
Moisés da Silva Martins, Aderaldo José Zocante, Lucas Videira da Silva, Victor Augusto da Silva \\ Carvalho
}

Universidade do Oeste Paulista - UNOESTE, Curso de Administração. FATEC, Cursos de Administração e Agronegócios Presidente Prudente, SP. E-mail: moises@unoeste.br

\section{RESUMO}

O presente estudo teve como objetivo geral investigar e analisar a composição do custo de produção da cana de açúcar em uma usina na alta Paulista. A pesquisa foi assim caracterizada: quanto à sua natureza, como aplicada; quanto ao objetivo, como exploratória; quanto à abordagem, quantitativa com método de modelagem e qualitativa com método de estudo de caso, utilizando método de pesquisa a entrevista com o responsável pela contabilidade da Usina. Para validação do estudo de caso, será realizado levantamento bibliográfico, auxiliando na definição do instrumento de coleta e nos procedimentos de análise de dados, Os resultados demonstraram que o custo total por tonelada da cana de açúcar na Região foi de $\mathrm{R} \$ \mathbf{8 6 , 6 4}$ considerando parceria/arrendamento e $\mathrm{R} \$ \mathbf{9 4 , 7 0}$ considerando parceria/fornecedor.

Palavras-Chave: Agricultura. Pequeno produtor. Rentabilidade. Cana de açúcar.

\section{COMPARISON OF INDUSTRIAL AND ADMINISTRATIVE COSTS IN DR-10 SUGAR AND ALCOHOL PLANTS: PRUDENT PRESIDENT REGION}

\begin{abstract}
The present study had as general objective to investigate and analyze the composition of the production cost of the sugar cane in a plant in the Paulista high. The research was thus characterized: as to its nature, as applied; as to the objective, as exploratory; regarding the quantitative approach with modeling and qualitative method with case study method, using the interview method with the responsible for the accounting of the Plant. To validate the case study, a bibliographic survey will be carried out, helping to define the collection instrument and data analysis procedures. The results showed that the total cost per ton of sugarcane in the Region was $\mathrm{R} \$ 86.64$ considering partnership / lease and $\mathrm{R} \$ 94.70$ considering partnership / supplier.
\end{abstract}

Keywords: Agriculture. Small producer. Profitability. Sugar cane.

\section{INTRODUÇÃO}

Nas últimas décadas, frente aos avanços relevantes no cultivo de cana de açúcar em todo o Brasil, sendo este o atual líder mundial no setor sucroalcooleiro, com a produção de cana de açúcar mais concentrada nos Estados de São Paulo, Paraná e Minas Gerais, onde São Paulo é o maior produtor de cana de açúcar, e entre os primeiros produtores está o Estado de Minas Gerais, com a produção mais concentrada na região do Triângulo Mineiro e Alto Paranaíba (CARVALHO \& OLIVEIRA, 2006; SOUSA \& CLEPS JUNIOR, 2014).

Frente a esses destaques produtivos, o presente estudo adota como objetivo a compreensão sobre como dá-se o custo de produção da cana de açúcar na região da alta Paulista. 
Trata-se de um estudo complexo que abrange aspectos quantitativos e qualitativos, em virtude da pluralidade de dados e informações que envolvem a análise.

Para Bornia (2010) o ideal é que todos os fatores de produção devam ser remunerados, composto pelos custos fixos e variáveis para se chegar ao custo total da produção, para que assim permita a real parametrização do preço inicial do produto cana de açúcar. A problemática surge em como o custo de produção é mensurado, uma vez admitindo que haja alocação indevida na sua classificação, possibilitando assim que o cálculo de custos de um produto de determinada atividade agrícola seja alocado indevidamente. Sob esse aspecto, o empresário rural deva adotar os gastos para a formação do bem, após o reconhecimento dos gastos para a produção, estabelecer a correta classificação e alocação dos custos, e após o produto acabado contabilizar os demais gastos como despesa.

O presente estudo permite algumas contribuições para o setor sucroalcooleiro, como por exemplo, chegar a uma estimativa de custo total de produção da cana de açúcar, já que o estudo destaca a importante diferença entre custos e despesas. Como objetivos secundários, o presente estudo possibilita reflexões sobre quais variáveis constituem os custos operacionais efetivos e totais para a referida região de estudo, de modo a cooperar com a viabilidade do negócio.

\section{MÉTODOS}

Para adequar a metodologia o problema surge em como o custo de produção é mensurado, uma vez admitindo que haja alocação indevida na sua classificação, possibilitando assim que o cálculo de custos de um produto de determinada atividade agrícola seja alocado indevidamente. Sob esse aspecto, o empresário rural deva adotar os gastos para a formação do bem, após o reconhecimento dos gastos para a produção, estabelecer a correta classificação e alocação dos custos, e após o produto acabado contabilizar os demais gastos como despesa.

Foi aí que o presente estudo adotou como objetivo a investigação e análise da compreensão sobre como se dá o custo de produção da cana de açúcar em uma usina de produção a álcool e ou açúcar. Verificando os padrões de custos da unidade estudada avaliando os custos da usina pesquisada e chegando a uma estimativa de custo total de produção da cana de açúcar,

O trabalho seguiu o preceito de estudo exploratório descritivo, por meio de uma pesquisa bibliográfica, considerando informações de livros, artigos científicos e periódicos correspondentes à área do agronegócio em especial a produção da cana de açúcar.

Para concretizar pesquisa, o pesquisador foi até a usina em estudo e colheu as informações necessárias para o estudo de custos e lucratividade.

Partindo de uma concepção metodológica adotada por Turrioni e Melo (2012), em que elaboraram uma estrutura lógica com os elementos básicos para se construir uma metodologia de pesquisa, o presente estudo classifica-se da seguinte forma: natureza, objetivos, abordagem e método. Quanto à natureza, esta pesquisa é considerada aplicada, pois se caracteriza por seu interesse prático, ou seja, que os resultados sejam utilizados seguidamente na solução de problemas que ocorrem na realidade. Quanto ao objetivo, a pesquisa é descritiva por descrever as características de determinada população ou fenômeno ou o estabelecimento de relações entre variáveis. De modo que possam ser envolvidos os usos de técnicas padronizadas de coleta de dados: questionário e a observação sistemática. Para esse estudo, a padronização objetiva apenas levantar a composição de custos, e em seguida classificar e adequar aos respectivos métodos de custos.

\section{RESULTADO}

Na propriedade onde tem se uma área de contrato de 788,27 ha, sendo 769,17 ha de cana e 19,10 ha de carreadores, ou seja, 325,73 alqueires de área útil, 317,84 alqueires de cana e 7,89 
alqueires de carreadores, estimou-se colher na safra 14/15 cerca de 40.673,32 toneladas de cana em uma área 753,99 ha disponível para a referida safra, isto é, 53,94 toneladas/ha, porém obtevese apenas $36.351,37$ toneladas, ou seja, 48,21 toneladas/ha, desta forma, obteve-se uma quebra de produtividade de $10,63 \%$ em relação ao estimado, esta quebra significa $4.321,950$ toneladas a menos na agroindústria.

Ao notar que a produtividade da propriedade quase não pagava ao arrendamento, a usina realizou a reforma do canavial durante a safra 15/16 e neste ano não realizou a colheita da área.

Na safra seguinte, $16 / 17$, primeira colheita após a reforma, estimou-se uma produtividade de 135 toneladas/ha, ou seja, 100.253,70 toneladas de cana nos 742,62 ha disponíveis para a referida safra, porém colheu-se cerca de 123.101,24 toneladas de cana, o equivale uma produtividade de 165,77 toneladas/ha, o que equivale a uma variação de $22,79 \%$ a mais de toneladas colhidas, isto significa que a usina moeu $22.847,54$ toneladas a mais do que esperado para esta safra.

Já na safra 17/18 havia uma área disponível de 760,17 ha de cana, que se estimou colher aproximadamente $79.869,38$ toneladas o que significa uma produtividade de 105,07 toneladas/ha, mas conseguiu atingir apenas 104,89 toneladas/ha, o que significa 79.735,91 toneladas de cana entregue na usina, isto significa uma variação negativa de $0,17 \%$ em relação ao estimado, ou seja, 133,47 toneladas a menos para ser processada.

Por fim na safra 18/19 estimou-se uma produtividade de 83,40 toneladas/ha, ou seja, uma produção de $64.152,30$ toneladas de cana nos 769,17 ha disponíveis para a referida safra, porém entregou-se apenas 57.054,97 toneladas, o que significa uma produtividade de 74,18 toneladas/ha e uma variação negativa de $11,06 \%$, ou 7.097,33 toneladas a menos na produção.

Com relação às 4 safras estudadas, projetou-se colher $284.948,70$ toneladas de cana em uma somatória de área de aproximadamente 3.025,95 ha, o que significa uma produtividade média 94,17 toneladas/ha, no entanto, colheu cerca de 296.243,49 toneladas o que representa 97,90 toneladas/ha, o que corresponde a uma variação positiva de 3,96\% durante o período, que se traduz em 11.294,790 toneladas a mais sendo processada em relação às projeções.

O trabalho seguiu o preceito de estudo exploratório descritivo, por meio de uma pesquisa bibliográfica, considerando informações de livros, artigos científicos e periódicos correspondentes à área do agronegócio em especial a produção da cana de açúcar.

Para concretizar pesquisa, o pesquisador irá até a usina em estudo e colherá as informações necessárias para o estudo de custos e lucratividade.

Partindo de uma concepção metodológica adotada por Turrioni e Melo (2012), em que elaboraram uma estrutura lógica com os elementos básicos para se construir uma metodologia de pesquisa, o presente estudo classifica-se da seguinte forma: natureza, objetivos, abordagem e método. Quanto à natureza, esta pesquisa é considerada aplicada, pois se caracteriza por seu interesse prático, ou seja, que os resultados sejam utilizados seguidamente na solução de problemas que ocorrem na realidade. Quanto ao objetivo, a pesquisa é descritiva por descrever as características de determinada população ou fenômeno ou o estabelecimento de relações entre variáveis. De modo que possam ser envolvidos os usos de técnicas padronizadas de coleta de dados: questionário e a observação sistemática. Para esse estudo, a padronização objetiva apenas levantar a composição de custos, e em seguida classificar e adequar aos respectivos métodos de custos.

\section{DISCUSSÃO}

Dentre os vários tipos de custos, estão os custos diretos e indiretos. A relação dos custos diretos e indiretos é feita de acordo com o produto ou serviço prestado, não sendo associado à produção no sentido geral ou as divisões dentro da organização. Sendo assim, a diferença entre 
esses dois tipos de custos é que custos diretos são os custos que podem ser diretamente apropriados aos produtos em que é necessário ter uma medida de consumo.

Caso os produtos que não apresentem alguma forma de medida objetiva, são definidos como custos indiretos (MARTINS, 2003). Em paralelo, Santos (2011), reforça que os custos indiretos são custos com mão de obra e materiais necessários para a produção que não são identificados nos processos de produção. $O$ autor aborda que os custos indiretos de produção se subdividem em relação ao volume de produção, ao controle e aos departamentos. Em relação ao volume de produção, é muito vantajoso saber qual o relacionamento do procedimento dos custos indiretos de uma produção, descobrindo quais são os elementos essenciais para a composição dos cálculos de custos de produção e de vendas.

Em relação ao controle, o autor ainda aborda que os custos indiretos nessa categoria são classificados em custos controláveis e custos não controláveis. Os custos controláveis são custos controlados por uma pessoa designada para essa atividade, que fica responsável pelos gastos de sua atividade. Já os custos não controláveis são custos que não são controlados por níveis hierárquicos.

Sobre os custos indiretos de produção relacionados com os departamentos produtivos e de serviços, o autor afirma ainda que os objetivos para ter uma divisão em departamentos dentro de uma entidade são para obter uma apropriação mais clara e exata dos custos incorridos dentro da empresa e para ter um controle maior dos custos de cada departamento. Com a departamentalização, os custos indiretos vão diminuir, pois vão se tornar diretos em relação aos próprios departamentos (SANTOS, 2011).

Reforçando os conceitos de custos diretos e indiretos, Bornia (2010), expõe que os custos diretos estão diretamente relacionados com as unidades do produto fabricado ou serviço prestado. Enquanto os custos indiretos, o autor classifica como custos que não são facilmente concedidos às unidades, ou seja, produtos que não possuem medidas facilmente definidas. Sob uma definição complementar, adotada por Martins (2003), entende-se por ser a diferença entre custos fixos e variáveis, onde é levada em consideração a relação entre o valor total de um custo e o volume de produção em um determinado período. Compreendendo-se, portanto, que os custos fixos são os custos que não tem seu montante fixado em função de oscilação na atividade durante um período, e os custos variáveis são os que possuem seu valor determinado em função desta oscilação.

Finamente, considera-se que este estudo objetivou analisar e investigar o custo de produção da cana de açúcar em uma usina sucroalcooleira da nossa região. Em termos gerais, foi possível apresentar a composição de custos da cana de açúcar sob seus respectivos estágios de atuação em dois diferentes contratos realizados pela usina investigada. Os resultados demonstraram que o custo total por tonelada da cana de açúcar na Região foi de $\mathrm{R} \$ \mathbf{8 6 , 6 4}$ considerando parceria/arrendamento e $\mathrm{R} \$ 94,70$ considerando parceria/fornecedor. Depreendese que há maior vantagem, em termos de custo, com parcerias em arrendamento para plantio, corte e colheita, o que demandaria esforços em investimentos agrícolas e aquisições estruturais em virtude do valor desembolsado por tonelada de cana de açúcar.

\section{REFERÊNCIAS}

BORNIA, Antonio Cezar. Análise gerencial de custos: aplicação em empresas modernas. 3. ed. São Paulo: Atlas, 2010.

CARVALHO, Glauco Rodrigues; OLIVEIRA, Clesiane de. O setor sucroalcooleiro em perspectiva. Campinas: Embrapa Monitoramento por Satélite, 2006. (Circular Técnica, 10). Disponível em: http://www.cnpm.embrapa.br/publica/download/cit10_sugaralcool.pdf>. Acesso em: 12 fev. 2014. 
CEPEA, ESALQ USP. Potencial de produção a partir do investimento. 2010. Disponível em: <http://www.cepea.esalq.usp.br/leite/custos/2011/09Set.pdf>. Acesso em: 20 nov. 2013.

GIL, Antônio Carlos. Como elaborar projetos de pesquisa. São Paulo: Ed. Atlas, 2002. 175p.

LAMPKOWSKI, Francisco José. Estratégia de produção: Inovação tecnológica no processo de corte da cana de açúcar como fator competitivo. Bauru, 2004.

MARTINS, Eliseu. Contabilidade de Custos - 9. ed. - São Paulo : Atlas, 2003.

SANTOS, Joel José. Contabilidade e análise de custos. 6. ed. São Paulo: Atlas, 2011.

TURRIONI, João Batista; MELLO, Carlos Henrique Pereira. Metodologia da Pesquisa em Engenharia de Produção. Universidade Federal de Itajubá, Programa de pós-graduação em engenharia de produção, 2012. 